\title{
Pendidikan Karakter Berbasis Tasawuf
}

\section{Nama: Andrean Purnomo}

\section{Email: Andrean13041998@gmail.com}

\section{Pendahuluan}

Pada zaman modern saat ini, banyak sekali orang tua yang bangga bila anak-anaknya mengikuti les matematika atau mata pelajaran umum lainnya dari pada les pendidikan agama (membaca al-Quran dan sebagainya). Terdapat seorang guru yang mengeluh karena dalam satu kelas hanya ada beberapa anak yang mempunyai kamus bahasa arab sedangkan yang lainnya mayoritas mempunya kamus bahasa inggris. Hal ini menggambbarkan bahwa anakanak dan orang tua lebih mementingkan materi pelajaran umum (B inggris) dari pada pelajaran bahasa arab.

Melihat dari kondisi diatas, maka sangat penting ilmu tasawuf untuk diajarkan dalam pendidikan yang serba modern pada saat ini. Kharisudin aqib menyatakan bahwa secara istilah tasawuf sebagai ilmu adalah suatu pengetahuan yang membahas seluk beluk hubungan antara manusia dan tuhannya. Sedangkan junaidi al Baghdad menyatakan bahwa tasawuf merupakan suatu keniscayaan bahwa dalam kondisi apapun dan dimana pun kita harus tetap mengingat Allah.

Berbeda dengan Ma'ruf Al-Karoqhi yang menyatakan bahwa tasawuf adalah mencari hakikat dan meninggalkan dari segala sesuatu yang ada pada tangan makhluk. Ibdu khaldun mengatakan bahwa tasawuf merupakan semacam ilmu syariah yang kemudian timbul di dalam agama, awalnya adalah rajin dalam beribadah dan memutuskan pertalian dengan segala sesuatu selain Allah, hanya menghadap allah semata, menolak hiasan-hiasan dunia yang membutakan hati kita serta membenci perkara-perkara yang memperdayakan banyak orang, kenikmatan harta benda serta kemegehan duniawi dan hanya focus menuju jalan Allah dalam halwat dan ibadah.

Abdul karim amrullah mengatakan bahwa tasawuf adalah sebagai pembersih jiwa dari pengaruh benda atau alam agar ia mudah menuju ke jalan yang benar. Sedangkan Labib MZ dan Moh. Al aziz mengatakan bahwa tasawuf merupakan pendekatan diri kepada allah dengan beribadah membersihkan diri dan hati dari sifat tercela, menghiasi diri dengan sifat 
terpuji, tidak mengutamakan urusan dunia, merasa cukup dan bersyukur dengan yang allah berikan kepada dirinya disertai tawakal dan mahabbah kepada Allah. Ditegaskan dalam kamus besar Bahasa Indonesia bahwa tasawuf adalah ajaran untuk mengenal dan mendekatkan diri kepada Allah sehingga memperoleh hubungan langsung dengan sadar kepada Allah. ${ }^{1}$

Kegunaan ilmu tasawuf dapat mengatasi masalah moral yang sekiranya memiliki batasan-batasan tasawuf karena itu telah dipandang sebagai lemahnya daya juang di kalangan umat islam. Menurut paham mistisisme ajaran tasawuf mempunyai tujuan untuk memperoleh hubungan langsung dan juga di dasari oleh tuhan. Sikap yang seperti ini sangat di perlukan oleh masyarakat modern yang telah mengalami jiwa terpecah sebagai penerapan dalam merespon dari berbagai masalah yang di hadapinya.

Mengingat pentingnya dari pemahaman ilmu tasawuf ini guna untuk diterapkan dalam kehidupan, maka dari itu diperlukan transformasi nilai tasawuf kepada generasi penerus dalam pendidikan taswuf melalui iman, islam, dan ihsan yang diejawantahkan dalam sebuah perilaku. Didalam hal pendidikan model seperti ini, ibn khaldun mempunyai pendapat bahwa menusia merupakan makhluk berfikir atau mempunyai akal. Kemampuan berfikir seperti ini masih berbentuk potensi (fitrah) yang akan bisa menjadi actual melalui sebuah pendidikan. ${ }^{2}$

Dari pernyataan tersebut diatas maka penulis menggaris bawahi bahwa tasawuf merupakan ilmu pengetahuan hubungan antara manusia dengan tuhannya, keadaan beserta Allah, mencari kebenaran dengan meninggalkan segala yang ada pada tangan makhluk, semacam ilmu syariat untuk menghap dengan Allah, membersihkan jiwa untuk menuju ke jalan yang benar, dan untuk mendekatkan diri kepada Allah ${ }^{3}$.

Bertitik tolak pada esensi-esensi pendapat diatas, maka saya sebagai penulis menyimpulkan bahwa pengertian tasawuf adalah ajaran atau ilmu pengetahuan untuk mencari hakikat dan membersihkan jiwa, serta berserah diri dan mendekatkan diri kepada allah, guna mendapatkan ketentraman jiwa, ketenangan hati dan kebahagiaan di dunia dan di akhirat. ${ }^{4}$

\footnotetext{
${ }^{1}$ Aplikasi Tasawuf, 'Mashudi - Aplikasi Tasawuf' 2, no. November (2015): 2.

2 Ali Mustofa, 'KECERDASAN SPIRITUAL DAN KARAKTER' 4, no. 1 (2018): 4.

${ }^{3}$ Muhammad Anas Ma`arif and Muhammad Husnur Rofiq, 'Dzikir Dan Fikir Sebagai Konsep Pendidikan Karakter: Telaah Pemikiran KH. Munawwar Kholil Al-Jawi', Tadrib: Jurnal Pendidikan Agama Islam 5, no. 1 (1 July 2019): 1-20, https://doi.org/10.19109/tadrib.v5i1.3066.

4 Tasawuf, 'Mashudi - Aplikasi Tasawuf'.
} 


\section{Pembahasan}

\section{Definisi Tasawuf}

Pengertian tasawuf dikemukakan oleh banyak ahli, antara lain, yaitu:

a) Menurut Muhammad bin Ali Qassab Tasawuf adalah akhlak yang terpuji, yang tampak di masa yang mulia, dari seorang yang mulia, bersama dengan orang yang mulia.

b) Menurut Ruwaim, tasawuf adalah jiwa yang menurut (taat- pen.) kepada Allah SWT sesuai dengan kehendak-Nya. Ada juga ulama yang mengatakan tasawuf adalah pikiran satu hati yang penuh dengan konsentrasi bersandar kepada Allah SWT dan perbuatan yang bersandar pada kitabullah dan Rasul-Nya.

c) Menurut Al-Junaidi, tasawuf adalah hendaklah kamu bersama Allah SWT saja tidak punya hubungan lain selain kepada Allah.

d) Menurut Ibnu Ujaibah, tasawuf adalah ilmu yang dengannya diketahui cara untuk mendekatkan diri kepada Allah SWT, membersihkan batin dari semua akhlak buruk (tercela) dan menghiasinya dengan beragam akhlak terpuji. Ilmu adalah awal dari akhlak tasawuf, Sedangkan amal adalah tengahnya, dan akhirnya adalah karunia. ${ }^{5}$

Dalam islam Sufi (pengamal ajaran tasawuf) merupakan maqam tertinggi dimana orang yang membersihkan dari sesuatu yang tercela dan menghiasi dirinya dari sesuatu yang baik. $^{6}$ Dan apabila seseorang telah dekat dengan Allah dan meraih cinta-Nya, semua karena kemuliaan akhlaknya, maka secara otomatis ia pun akan dekat dan dicintai oleh sesama manusia. Sampai sekarang pemahaman itu tetap menjadi pedoman.Tasawuf kontemporer tidak jauh berbeda dari kontek ajaran tasawuf klasik. Tetapi tidak memiliki silsilah secara langsung terhadap tasawuf klasik. Kalau masih ada silsilah, tentu saja ia masih masuk kategori tasawuf klasik.

Tasawuf kontemporer terdapat di wilayah masyarakat kota mengambil ajaran tasawuf dan mengemasnya menjadi industri baru berbasis agama karena dibutuhkan oleh masyarakat kota. pasar tasawuf tumbuh dan masuk wilayah komunikasi massa dan teknologi karena

\footnotetext{
5 ahmad sodiq, 'Dosen Fakultas Tarbiyah Dan Keguruan IAIN Raden Intan Lampung’, 2014, 9.

${ }^{6}$ Pendidikan Karakter and Berbasis Tasawuf, 'Jurnal al Tarbawi al Haditsah Vol 1 No 1 Issn 2407-6805' 1, no. 1 (n.d.); Jurnal Studi Al- Qur et al., ‘Jurnal Studi Al- Qur’an; Membangun Tradisi Berfikir Qur'ani Vol. 10, No. 1, Tahun. 2014’ 10, no. 1 (2014): 1-19.
} 
kejenuhan masyarakat kota terhadap persaingan hidup. Tasawuf kontemporer merupakan penamaan yang berakar pada dasarnya dan berada pada barisan neo-sufisme Rahman dan tasawuf modern, yang diusung Hamka.Tasawuf modern, bagi Hambka, adalah penghayatan keagamaan esoteris yang mendalam tetapi tidak dengan serta merta melakukan pengasingan diri ('uzlah). Neo- sufism menekankan keterlibatan diri sangat di perlukan dalam masyarakat secara lebih dari pada sufisme terdahulu. Neo Sufism cenderung kembali menghidupkan aktifitas salafi dan kembali menanamkan sikap positif terhadap kehidupan ${ }^{7}$.

Pencapaian yang hendak ditujukan oleh tasawuf kontemporer adalah sama dengan konsep para sufi terdahulu (sufi klasik), seperti kedekatan (qurb) dengan Allah.Kehadiran Allah dalam kehidupan sehari-hari (muroqobah), dan menjadi al-Insan al-Kamil. Melihat coraknya, pengembangan tasawuf kontemporer mengarah kepada tubuhnya tasawuf akhlaqi, yang lebih mengedepankan sikap kesahajaan dan ibadah untuk mencapai kedamaian hidup dan kedekatan diri dengan Allah, yang harus dilalui dari tahap pensucian diri (tazkiyat alNafs).Setiap orang bisa menempuh cara-cara ke arah itu dengan melalui penyucian hati, konsentrasi dalam berdzikir, dan fana` fillah atau mukasyafah. ${ }^{8}$

\section{Pendidikan Karakter}

Pendidikan adalah upaya yang dilakukan dengan sadar untuk menimbulkan perubahan sikap dan tingkah laku seseorang melalui pengajaran dan latihan (Ensiklopedi Nasional Indonesia, 2004: 365). Sedangkan pendidikan dalam arti luas ialah terdiri dari usaha atau generasi tua untuk mengalihkan (melimpahkan) pengetahuannya, pengalamannya, kecakapannya beserta keterampilannya kepada generasi muda, sebagai sebuah usaha untuk menyiapkan mereka supaya bisa memenuhi fungsi hidupnya, baik dalam jasmaniah maupun rohaniah (Mansur 2011:84). Pendidikan dipandang sebagai keseluruhan daya budaya yang berpengaruh kepada kehidupan perseorangan ataupun kelompok dalam masyarakat (As-Said, 2011: 11). ${ }^{9}$

Pendidikan karakter adalah suatu sistem penanaman nilai-nilai karakter terhadap warga sekolah yang terdiri dari komponen pengetahuan, kesadaran atau kemauan, tindakan untuk melaksanakan nilai-nilai tersebut. Pendidikan karakter dapat diartikan sebagai berikut "the deliberate use of all dimensions of school life to foster optimal character development".

\footnotetext{
${ }^{7}$ Muhammad Anas Ma`arif, 'Tasawuf Falsafi Dan Implikasinya Dalam Pendidikan Islam', Vicratina: Jurnal Pendidikan Is/am 3, no. 1 (13 September 2018), http://riset.unisma.ac.id/index.php/fai/article/view/1026.

${ }^{8}$ Karakter and Tasawuf, 'Jurnal al Tarbawi al Haditsah Vol 1 No 1 Issn 2407-6805', 12.

9 Telaah Kitab and Sullam Taufiq, 'SYAIKH ABDULLAH BIN HUSAIN BA' ALAWI SKRIPSI', $2015,25$.
} 
Di dalam pendidikan karakter yang ada di dalam sekolah, harus melibatkan semua komponen (pemangku pendidikan), termasuk komponen-komponen pendidikan itu sendiri, yaitu isi dari kurikulum proses penilaian dan pembelajaran, penanganan atau pengelolahan mata pelajaran, pengelolaan sekolah, pelaksanaan aktifitas, atau kegiatan kon-kurikuler, pemberdayaan sarana dan prasarana, pembiayaan, dan ethos kerja seluruh warga sekolaha/lingkungan. Selain itu, pendidikan karakter diartikan sebagai suatu perilaku warga sekolah dalam menyelenggarakan pendidikan yang harus berkarakter ${ }^{10}$.

Menurut David Elkind \& Freddy Sweet Ph.D , pendidikan berkarakter diartikan sebagai berikut: "character education is the deliberate effort to help people understand, care about, and act upon core ethical values. When we think about the kind of character we want for our children, it is clear that we want them to be able to judge what is right, care deeply about what is right, and then do what they believe to be right, even in the face of pressure from without and temptation from within"

Selanjutnya dijelaskan bahwa pendidikan karakter adalah segala upaya yang dilakukan guru, yang mampu mempengaruhi karakter seorang peserta didik. Guru membantu membentuk watak seorang peserta didik. Hal ini mencakup bagaimana sikap seorang guru kepada peserta didik, cara guru berbicara dan menyampaikan materi kepada peserta didik, bagaimana seorang guru bertoleransi, dan berbagai hal yang terkait dengan lainnya.

Menurut T.Ramli, pendidikan karakter mempunyai esensi dan arti yang sama dengan pendidikan moral ataupun pendidikan akhlak. Tujuannya tidak lain untuk membentuk pribadi seorang peserta didik, supaya menjadi manusia yang berakhlak, berwarga masyarakat yang baik, dan warga negara yang baik. Adapun ciri-ciri manusia yang baik adalah berwarga ataupun bermasyarakat yang baik atau menjadi warga negara yang baik bagi masyarakat atau bangsa secara umum adalah nilai-nilai social tertentu, yang sudah banyak di pengaruhi oleh budaya dan bangsanya. Maka dari itu, hakikat dari pendidikan karakter yang berada dalam konteks pendidikan di Indonesia ialah pendidikan nilai, yakni pendidikan nilai-nilai luhur yang bersumber dari budaya yang ada di Indonesia sendiri, dalam rangka membina kepribadian (karakter) generasi muda. ${ }^{11}$

10 Muhammad Anas Ma'arif and Muhammad Husnur Rofiq, 'The Model of Character Teacher: Phenomenology at Daruttaqwa Gresik Islamic Boarding School', ATTARBIYAH: Journal of Islamic Culture and Education 3, no. 2 (2 January 2019): 131-52, https://doi.org/10.18326/attarbiyah.v3i2.131-152.

${ }^{11}$ Qur et al., 'Jurnal Studi Al- Qur'an; Membangun Tradisi Berfikir Qur'ani Vol. 10, No. 1, Tahun. 2014 ', 6 . 


\section{Macam-macam pendidikan berbasis tasawuf}

Secara bahasa, syariah mempunyai arti jalan, peraturan, undang-undang yang membahas tentang suatu perbuatan. Dan berasal dari bahasa arab syarii'atun yang artinya menggariskan suatu aturan atau pedoman. Kemudian Syari'ah secara istilah ialah undangundang yang telah dibuat oleh Allah yang berdasarkan iman dan islam, berupa seperangkat hukum yang diwahyukan dalam al-Qur'an dan as-Sunnah tentang perbuatan dhahir. Dengan makna yang seperti ini, maka syari'ah mempunyai makna yang sama dengan islam atau ad ddin.

\section{Haqiqah}

Haqiqah menurut bahasa artinya yang nyata, yang sejati dan yang benar. Haqiqah menurut istilah yang dimana selanjutnya ditulis dengan kata hakikat ialah telah sampainya seorang sufi yang menempuh jalan spiritual thariqah untuk menuju kepadanya yaitu mengenal Allah dan menyaksikan cahaya wujud dari Allah, yang dimana menurut al-Quraisy ialah menyelami hadirat suci ketuhanan, yakni artinya seorang melihat kebesaran Allah dengan hatinya.

Haqiqah ialah pemahaman yang sudah menetap dihati seseorang, bahwa tiada yang disembah selain Allah, tidak ada suatu kejadian tanpa ada perintah dari Allah, tidak ada yang memberi anugrah dan mencegahnya kecuali Allah, dan tidak ada ketergantungan apapun selain kepada Allah. Dari penjelasan yang telah dipaparkan diatas dapat kita pahami bahwa haqiqah ialah suatu tujuan atau inti, dari realita yang sebenarnya yang menyatakan bahwa haqiqah didalam pembahasan ini mengarah kepada pengetahuan batin yang mendalam tentang sesuatu.

\section{Ma'rifat}

Menurut bahasa Ma'rifat artinya mengenal, mengerti, mengetahui dengan daya qalbiyah. Menurut istilah Ma'rifat ialah mengenal nama-nama Allah beserta sifat-sifatnya, selalu menyebut namanya dalam semua keadaan atau dalam semua kondisi suasana dan mengembalikan segala sesuatu hanya kepadanya.

Pemaparan tentang syari'ah, thariqah, haqiqah dan ma'rifat diatas telah memberikan sebuah gambaran bahwa betapa seriusnya ulama sufi dalam usahanya memberi jalan bagi 
umat supaya mengamalkan ajaran agama islam dengan mudah dan tepat sehingga bisa membuat seluruh umat islam menuju kebahagiaan dzahir dan batin. ${ }^{12}$

\section{Hubungan Tasawuf Modern Dengan Pendidikan Islam}

Hakikatnya seorang manusia memiliki tiga dimensi utama, yaitu badan, akal dan roh. Apabila dari tiga dimensi ini dapat terpenuhi, maka seorang manusia tersebut dapat di katakan sebagai manusia yang sempurna. Mempunyai jasmani yang sehat, memiliki kecerdasan intelektual serta mempunyai pengetahuan yang luas dan memiliki kehidupan rohani yang berkualitas tinggi. Maka hal yang seperti inilah yang dapat disebuut sebagai Insan Kamil. Predikat tersebut bisa di dapatkan melalui usaha-usaha dalam pencapaiannya. Pada hakikatnya, segala usaha untuk memelihara dan mengembangkan fitrah seorang manusia yang ada padanya untuk menuju terbentuknya manusia seutuhnya (Insan Kamil) sesuai dengan norma islam, itu semua merupakan sebuah bentuk dari pendidikan islam. (Achmadi , 2008: 28-29). Yang dimaksud dengan Insan kamil adalah manusia yang mampu memformulasikan secara garis besar sebagai pribadi muslim atau juga bisa dapat diartikan sebagai "manusia yang beriman dan bertakwa serta memiliiki berbagai kemampuan yang teraktualisasi dalam hubungannya dengan tuhannya, hubungan atara sesame manusia maupun hubungan dengan alam yang ada di sekitarnya secara baik, positif dan kontruktif. ${ }^{13}$

Didalam pendidikan islam juga mengarahkan kepada tiga dimensi utama diatas untuk mengembangkannya. Dari tiga dimensi tersebut menunjukkan, bahwa selain memiliki kualitas fisik yang sehat, manusia juga perlu memperhatikan kualitas keorhaniannya, oleh sebab itu diperlukannya sebuah ilmu yang mampu membantu manusia agar tercapainya kualitas rohani yang di inginkan. Salah satu ilmu tersebut adalah ilmu tasawuf, dikarenakan pembahasannya yang mengenai hubungan antara Ma'bud dengan 'Abid, serta hubungan antara sesama manusia.

Oleh karena itu, tidak ada bedanya dengan pendidikan non islam, jika pendidikan islam tidak di warnai dengan ilmu tentang kerohanian, yang dimana pendidikan tersebut hanya membahas tentang pengetahuan tanpa ada nilai-nilai islam di dalamnya,yang dapat menimbulkan pemahaman rasionalisme, dimana rasio (akal) menjadi sesuatu yang di banggakan dan diagungkan. Tetapi tidak menutup kemungkinan, muncul sebuah pemahaman

\footnotetext{
${ }^{12}$ Mustofa, 'KECERDASAN SPIRITUAL DAN KARAKTER', 7.

${ }^{13}$ Muhamad Rifa, 'Pendekatan Sufistik Dalam Pendidikan Islam ( Telaah Pemikiran Hamka )', Artikel 1
} (2016): 9 . 
yang menganggap God Is Dead, yang bisa mengakibatakan kehidupan manusia jauh dari sentuhan religious (Abdurahman Mas'ud, 2001: 3). ${ }^{14}$

\section{Metode Dan Media}

Dalam penerapan pangajaran Al-Ghazali, ada tiga metode yang di terapkan didalam pembelajaran yang terdiri dari tiga aspek, pskologis, sosiologis, dan pragmatis dalam hal keberhasilan pembelajaran. Di dalam pengajaran Al-Ghazali bisa di contohkan dari metode yang digunakan misalnya, metode mujahadah dan metode riyadlah, pendidikan praktek dalam kedisiplinan, pembiasaan, penyajian dalil aqli dan naqliserta bimingan dan nasehat. Pemikiran yang berada diatas tataran kekinian menjadikan hal yang penting untuk di lakukan kembali, disamping metode dan media yang modern, sehingga akan terciptanya kelas yang ideal dalam pembelajaran, lebih bersifat monoton dan hal tersebut akan membuat siswa jenuh dan bosan sehingga dalam pembelajaran tersebut tidak ada interaksi yang baik serta dapat menurunkan semangat dan hasil belajar siswa itu sendiri. Maka seorang guru perlu mengubah pola pikirnya dalam menerapkan metode dan media pembelajaran yang pada saat ini semakain mudah untuk mendapatkan informasi dan alat-alatnya. ${ }^{15}$

\section{Metode Pendidikan Karakter Dalam Prespektif Tasawuf}

Ada empat cara untuk menerapkan strategi pelaksaan pendidikan karakter disekolah, yaitu : (1) pembelajaran (teaching), (2) keteladanan (modeling), (3) penguatan (reinforcing), dan (4) pembiasaan (habituating).

Efektivitas pendidikan karakter sangat ditentukan oleh adanya pembelajaran (teaching), keteladanan (modeling), penguatan (reinforcing), dan pembiasaan (habituating) yang dilakukan secara serentak dan berkelanjutan. Dari beberapa metode tersebut dijelaskan sebagai berikut:

1). Disaat komponen sekolah (kampus) sepenuhnya akan menerapkan dan melaksanakan nilai-nilai (karakter) tertentu (prioritas), maka setiap nilai yang akan ditanamkan atau dipraktikkan tersebut para guru harus senantiasa menyampaikan melalui pembelajaran langsung (sebagai mata pelajaran) atau mengintegraskannya ke dalam setiap mata pelajaran.

\footnotetext{
${ }^{14}$ Rifa, 10.

${ }^{15}$ B A B Iv, 'No Title', n.d., 7.
} 
2). Dari nilai-nilai prioritas tersebut selanjutnya harus juga dimodelkan (diteladankan) secara benar dan teratur serta berkesinambungan oleh semua warga sekolah(kampus), sejak dari petugas parkir, petugas kebersihan, petugas keamanan, karyawan administrasi,guru,dan pimpinan sekolah

3) Selanjutnya, nilai-nilai tersebut harus diperkuat oleh penataan lingkungan dan kegiataan-kegiatan di lingkungan sekolah (kampus). Penataan lingkungan di sini antara lain dengan menempatkan banner (spanduk-spanduk) yang mengarah dan juga memberikan dukungan atas terbentuknya suasana kehidupan sekolah (kampus) yang berkarakter terpuji. Penguatan dapat pula dilakukan dengan melibatkan komponen keluarga dan masyarakat. Komponen keluarga meliputi pengembangan dan pembentukan karakter di rumah, dari Pihak sekolah (kampus) para orang tua dapat dilibatkan agar lebih peduli terhadap perilaku para anak-anak mereka. Sedangkan komponen masyarakat atau komunitas secara umum adalah sebagai wahana praktik atau sebagai alat kontrol guna membentuk dan mengembangkan perilaku siswa (membentuk karakter mereka). Dari pihak sekolah (kampus) dapat melakukan komunikasi dan interaksi dengan keluarga dan masyarakat ini dari waktu ke waktu secara periodik ${ }^{16}$.

4) Dengan berbagai cara pembiasaan (habituation) tersebut dapat dilakukan dan menyangkut banyak hal seperti disiplin waktu, cara berpakaian yang baik, etika pergaulan, perlakuan siswa terhadap karyawan, guru, dan pimpinan, begitupun sebaliknya. Pembiasaan yang dilakukan oleh pimpinan, guru, siswa, dan karyawan, dalam disiplin suatu lembaga pendidikan merupakan langkah yang sangat strategis dalam mebentuk karakter secara bersama Selanjutnya,

Selanjutnya, di sekolah pendidikan karakter yang diterapkan semestinya terarah pada pengembangan kultur edukatif yang mengarahkan peserta didik agar menjadi pribadi yang integral. ${ }^{17}$

${ }^{16}$ Muhammad Anas Ma`arif, 'Dhikr and Thinking Integration as Non-Dicotomic Character Education Development | Proceeding International Conference on Islamic Education (Icied)', 16 February 2018, http://conferences.uin-malang.ac.id/index.php/icied/article/view/435.

17 Try Riduwan Santoso and Lilis Cahrolis, 'CRITICAL ANALISYS: KONSEP PENDIDIKAN KARAKTER' 2, no. 2 (2018): 10. 


\section{Nilai-nilai pendidikan karakter pada ajaran cinta dalam tasawuf}

Dalam ajaran tasawuf terdapat nilai-nilai pendidikan karakter yang terkandung pada wujud cinta yaitu didalam kehidupan beragamaan harus menumbuhkan sikap keharmonisan, berbangsa serta bernegara, ikhlas dalam beramal, adil dalam mengambil keputusan, toleransi, bertanggung jawab, demokratis, dan mempunyai rasa takut akan menyakiti hati sesama manusia karena itu dipandang sebagai dosa yang menjauhkan diri dari cintanya Allah SWT. Sehingga ketika kita mempunyai rasa takut tersebut maka dapat menciptakan kedamaian dalam bermasyarakat.

Melalui takhalli, tahalli, dan tajalli merupakan cara yang dapat ditempuh untuk mendapatkan cintanya, dengan beberapa tahapan-tahapan sabar, taubat, zuhud, faqr, tawaddu, taqwa, tawakkal, rida, dan cinta. Yang merupakan bagian dari nilai-nilai pendidikan karakter, tidak hanya terkait dengan hubungan sesama umat manusia saja, tetapi juga mempunyai keterkaitan antara hubungan manusia dengan Tuhan-Nya. Seseorang yang menjalankan sebuah tahapan untuk mendapatkan cinta pastinya akan terjaga dalam ucapan dan perbuatan yang menjukkan suatu karakter yang buruk. Maka sebaliknya akan menumbuhkan suatu karakter yang baik yaitu; beriman dan bertaqwa kepada Tuhan Yang Maha Esa, mempunyai akhlak yang mulia, sehat, berilmu, cakap, kreatif, mandiri, dan menjadi warga negara yang baik dan bertanggung jawab.

Adapun manfaat yang dapat diperoleh dalam konsep cinta tersebut adalah seseorang yang akan menjadi lebih dekat kepada Allah SWT. Jika peristiwa tersebut terjadi maka akan menimbulkan ketaatan dalam menjalankan perintah Allah dan menjauhi segala larangannya, sehingga nilai-nilai karakter dengan sendirinya akan tumbuh, contohnya seperti; rasa ketentraman dan kedamaian dalam bermasyarakat, mempunyai sikap religious yang diciricirikan dalam sikap hidup dan taat dalam beribadah, jujur, terpercaya, dermawan, mempunyai rasa saling tolong menolong, dan toleran. Mempunyai sikap moderat, yang diciri-cirikan dalam sikap hidup yang tidak radikal dan tercerminkan dalam kepribadian pertengahan antara social dan individual, berorientasi dalam rohani dan materi, serta mampu hidup dan dapat bekerja sama dalam hal kemajemukan. Sikap yang seperti itulah yang termasuk dapat dikatakan sebagai nilai-nilai pendidikan karakter. ${ }^{18}$

${ }^{18}$ Pada Ajaran and Cinta Dalam, 'NILAI-NILAI PENDIDIKAN KARAKTER PADA AJARAN CINTA DALAM TASAWUF Rahmi Damis UIN Alauddin Makassar’, 2014, 23. 


\section{Cara yang dapat ditempuh mendapatkan cintanya}

1. Takhalli

Tahap pertama yang harus dilakukan adalah sebuah usaha mengosongkan diri dari suatu sikap ketergantungan kepada kenikmatan dalam kehidupan duniawi, hal seperti ini dapat dicapai dengan cara menjauhkan diri dari kemaksiatan dalam berbagi bentuknya dan berusaha untuk melenyapkan dorongan hawa nafsu karena hawa nafsu tersebutlah yang menjadi sebab utama dari sikap yang buruk.

2. Tahalli

Tahalli merupakan suatu uapaya untuk mengisi dan menghasi diri dengan membiasakan diri dalam bersikap, berperilaku dan akhlak terpuji. Tahapan tahalli yang dilakukan oleh para kaum sufi dilakukan setelah jiwa dikosongkan dari akhlakakhlak yang buruk. Pada tahapan tahalli ini, supaya setiap gerak kaum sufi memiliki perilaku yang selalu berjalan diatas ketentuan agama.

\section{Tajalli}

Tajalli merupakan hialangnya hiajab dari sifat sifat kebasyariyahan (kemanusiaan), lebih jelasnya nur yang sebelumnya ghaib, dan fananya segala sesuatu ketika terlihatnya wajah Allah. Kata tajalli yang mempunnyai makna terungkapnya nur ghaib. Supaya hasil yang telah di dapatkan pada saat melakukan takhalli dan tahalli tidak berkurang, maka rasa ketuhanan harus lebih dihayati lebih dalam. Kebiasaan yang sering dilakukan dengan kesadaran dan rasa cinta dengan sendirinya akan menimbulkan sebuah kerinduan kepada-Nya. ${ }^{19}$

\footnotetext{
${ }^{19}$ Studi Multisitus et al., Pembentukan Karakter Siswa Berbasis Tasawuf Akhlaqi, 2018, 63.
} 


\section{Daftar pustaka}

ahmad sodiq. 'Dosen Fakultas Tarbiyah Dan Keguruan IAIN Raden Intan Lampung', 2014.

Ajaran, Pada, and Cinta Dalam. 'NILAI-NILAI PENDIDIKAN KARAKTER PADA AJARAN CINTA DALAM TASAWUF Rahmi Damis UIN Alauddin Makassar', 2014, 127-52.

Iv, B A B. 'No Title', n.d., 60-78.

Karakter, Pendidikan, and Berbasis Tasawuf. 'Jurnal al Tarbawi al Haditsah Vol 1 No 1 Issn 2407-6805' 1, no. 1 (n.d.).

Kitab, Telaah, and Sullam Taufiq. 'SYAIKH ABDULLAH BIN HUSAIN BA' ALAWI SKRIPSI', 2015.

Ma'arif, Muhammad Anas. 'Dhikr and Thinking Integration as Non-Dicotomic Character Education Development | Proceeding International Conference on Islamic Education (Icied)', $\quad 16 \quad$ February $2018 . \quad$ http://conferences.uinmalang.ac.id/index.php/icied/article/view/435.

. 'Tasawuf Falsafi Dan Implikasinya Dalam Pendidikan Islam'. Vicratina: Jurnal Pendidikan Islam 3, no. 1 (13 September 2018). http://riset.unisma.ac.id/index.php/fai/article/view/1026.

Ma`arif, Muhammad Anas, and Muhammad Husnur Rofiq. 'Dzikir Dan Fikir Sebagai Konsep Pendidikan Karakter: Telaah Pemikiran KH. Munawwar Kholil Al-Jawi'. Tadrib: Jurnal Pendidikan Agama Islam 5, no. 1 (1 July 2019): 1-20. https://doi.org/10.19109/tadrib.v5i1.3066.

Ma'arif, Muhammad Anas, and Muhammad Husnur Rofiq. 'The Model of Character Teacher: Phenomenology at Daruttaqwa Gresik Islamic Boarding School'. ATTARBIYAH: Journal of Islamic Culture and Education 3, no. 2 (2 January 2019): 131-52. https://doi.org/10.18326/attarbiyah.v3i2.131-152.

Multisitus, Studi, Qolam Man, Kota Malang, Darul Hikmah, and M A N Kota. Pembentukan Karakter Siswa Berbasis Tasawuf Akhlaqi, 2018.

Mustofa, Ali. 'KECERDASAN SPIRITUAL DAN KARAKTER' 4, no. 1 (2018): 111-39.

Qur, Jurnal Studi Al-, Membangun Tradisi, Berfikir Qur, and Jurnal Studi Al- Qur. 'Jurnal Studi Al- Qur'an; Membangun Tradisi Berfikir Qur'ani Vol. 10, No. 1, Tahun. 2014' 10, no. 1 (2014): 1-19.

Rifa, Muhamad. 'Pendekatan Sufistik Dalam Pendidikan Islam ( Telaah Pemikiran Hamka )'. Artikel 1 (2016): 62-88.

Santoso, Try Riduwan, and Lilis Cahrolis. 'CRITICAL ANALISYS: KONSEP PENDIDIKAN KARAKTER' 2, no. 2 (2018): 14-29.

Tasawuf, Aplikasi. 'Mashudi - Aplikasi Tasawuf' 2, no. November (2015). 